\title{
GEORGE SAND Y DON JUAN: SEDUCCIÓN ES FEMENINO SINGULAR
}

\author{
Elena Suárez Sánchez \\ Universidad de Sevilla
}

\begin{abstract}
George Sand succeeded in establishing herself among the French intellectual élite of the $19^{\text {th }}$ century. She was firmly convinced that women should be on a par with men and consequently she fought on various fronls to prove that ability is not a matter of sex. Her relentless hounding and eventual demolition of the figure of Don Juan, the archetype of the male mercilessly exploiting women for his own ends while spuming their wmlh as human beings, is aimed at putting forth the ideal of a new, strong, independent and self-sufficient woman who nevertheless retains her feminine signs of identity
\end{abstract}

La inquietud por el cambio parece invadir todos los ámbitos de la existencia de George Sand. Establecer un paralelismo entre la actividad a la que ésta se entrega por sus numerosos desplazamientos dentro y fuera de Francia y la agitación de su vida amorosa, sometida a una continua renovación, no resulta forzado. Sabiendo conjugar el placer del apego al terruño con la realización de viajes periódicos (Auvergne, Pirineos, Midi, Italia, España, Suiza), Sand da la impresión de complacerse en el balanceo entre la partida y el retomo como puntos siempre atractivos. Pareja vivacidad se observa en sus numerosas relaciones con el sexo opuesto en las que no resulta fácil establecer la línea divisoria entre la amistad y el romance. Ajasson de Grandsagne, Aurélien de Seze, Musset, Liszt, Chopin, Malefille, Michel de Bourges, Pierre Leroux, Bocage, Manceau, Marcha!, entre otros, protagonizaron con ella historias de camaradería y pasión, las más de las veces bastante tempestuosas.

Esta vida que podría calificarse cuando menos de trepidante iba a pasarle factura a la escritora por medio de la crítica acerva que recibiría de sus contemporáneos. Todo en esta polémica mujer se fue convirtiendo en motivo de reproche. Su vida sentimental por supuesto, así como su manera de vestir, sus teorías avanzadas sobre la reforma social. Pero era sobre todo su condición femenina la que chocaba a la hora de integrarse en los círculos intelectuales. No en vano, Charles Baudelaire la designaba despreciativamente como "la Jemme Sand".

Mucho antes de que se pudiera hablar de feminismo francés propiamente dicho, Sand militaba como mujer. Tanto en la vida real como en la literatura, la mujer es vista por Aurore Dupin como igual al hombre e incluso superior en algunos aspectos fundamentales. En la cuestión de la equiparación de sexos, Sand enlaza con las mujeres republicanas que en la Francia revolucionaria solicitaron que los ideales de libertad, igualdad y fraternidad se aplicaran de forma real a todo ser humano. Como es sabido, el Código Napoleónico, 
inspirado en el derecho romano, vino a cortar toda evolución en ese sentido. La aparición en Inglaterra en 1792 de una obra como la de Mary Wollstonecraft, Una reivindicación de los derechos de la mujer, era impensable en Francia, en donde habría que esperar mucho para que el movimiento feminista se organizara, dada la oposición que le ofrecía la Iglesia Católica, argumentando que destruía la familia patriarcal. Frente a esta tesis, Sand defendió abiertamente el amor libre en contra del matrimonio y luchó contra los convencionalismos desde muy temprana hora como puede observarse en las consideraciones que hace en Indiana y Valentine, obras de 1832.

Como pensadora, como teórica y practicante de un socialismo algo edulcorado y como escritora fue objeto de desautorizaciones implacables por parte de algunos coetáneos ilustres como Barbey d'Aurevilly o Nietzsche. En cambio, pudo gozar del reconocimiento de otros no menos influyentes como Flaubert y Sainte-Beuve. Si bien es cierto que una parte de su producción no soporta una revisión actual, ciertos destellos siguen teniendo hoy su brillo, destellos que hirieron a algunos autores de su época en el punto en donde nacen los celos artísticos. Muy probablemente, la herida pudo escocer aún más por lo desacostumbrado de la condición femenina de quien la infligia.

El huracán Sand tenía forzosamente que causar estragos. La ansiedad por ver sus múltiples proyectos hechos realidad debía provocar una gran dispersión tanto en su vida personal como en su producción literaria. Y es que realmente Sand no parece haber renunciado a nada. En su afán por atender a todos los frentes, no culminaba siempre lo que emprendía. Demasiado ambiciosa para limitarse a un campo específico, no consiguió encontrar un sitio que le perteneciera totalmente. En toda su trayectoria se percibe una inseguridad selectiva de objetivos debido a esa voracidad intelectual ya comentada. Su exuberancia creativa afecta con frecuencia a la longitud de sus obras, extremadamente extensas, hasta el punto de que a veces una novela desborda sus propios límites, debiendo continuarse en otra'. También su aporte epistolar -que contempla más de cerca su propia vida- constituye otra muestra de fertilidad narrativa².

En la primera etapa de su producción -cuyo punto de partida es el conjunto de colaboraciones con Jules Sandeau de quien tomará incluso la primera parte del apellido para construir su seudónimo- crea relatos cortos y novelas entre las que se encuentra Lélia. Dicha obra se publica en la casa editorial de Henri Dupuy y L. Tenré en dos volúmenes en 1833, siendo la única obra de Sand que Barbey admitió admirar. En 1839 Sand sacaría a la luz una nueva edición de Lélia muy retocada en la editorial de Félix Bonnaire, esta vez en tres volúmenes.

\footnotetext{
'Basta señalar el ejemplo de Consuelo y La Comtesse de Rudolstadt, dos novelas publicadas de 1842 a 1844 en la Revue Indépendante, que constituyen una unidad. Ambas son desmesuradas por la extensión y por la amplitud de la materia que abarcan. Imposible de calificar, este conjunto tiene, como había ocurrido con Lélia casi una década antes, rasgos de variados subgéneros narrativos: novela de aprendizaje, de viajes, de aventuras, de amor, histórica, negra ... Incluso se reserva en él un lugar privilegiado para la música y las ciencias ocultas.

${ }^{2}$ Las llamadas Lettres d'un voyageur fueron recopiladas y publicadas en un volumen en 1837. La Correspondance, inmensa, arranca de una nota de 1812 que Sand habría escrito a su madre siendo muy pequeña. Fue publicada de 1882 a 1884 en seis volúmenes por Calmann-Lévy.
} 
Esta obra tiene el acierto de adoptar una perspectiva distinta con respecto a uno de los personajes literarios célebres que serán recreados por los escritores románticos, el de Don Juan. En Lélia Sand adopta una postura discordante frente a lo que ya podía considerarse un mito moderno dada la cantidad de versiones que había generado, mito por el que sin embargo proclama no sentir ninguna fascinación. Su interés por et tema va encaminado fundamentalmente a denunciar el desprecio que se había hecho en las distintas versiones a la mujer al ser convertida en juguete de seducción masculina. Empezará pues por condenar absolutamente la práctica de engaños y de supercherías del personaje y la ligereza de todos aquellos que disculpaban su proceder al pensar que, en el fondo, la empresa de conquistar a las mujeres recurriendo al engaño y, si era preciso, a la violencia e incluso al crimen, suponía valores de virilidad y arrojo en el burlador. Seguidamente aprovecha para teorizar sobre el amor, afirmando que, para que llegue a ser auténtico, éste debe establecerse desde la asunción de la igualdad de los dos sujetos implicados en la relación. Por último, dibuja a una mujer que puede jugar al mismo juego de seducción impasible y de superioridad de género. Lo que podía parecer una fábula en palabras de cualquier otra persona tenía peligrosos visos de realidad viniendo de George Sand. Su repertorio de amantes bien valía cuando menos, la hipótesis de la factibilidad de una mujer Don Juan.

La historia de Don Juan había ido adquiriendo pátina desde su plasmación en la obra teatral El Burlador de Sevilla y combidado de piedra, atribuida en la edición de 1630 a Tirso de Molina ${ }^{3}$. El seductor tramposo que ultraja a vivos y muertos se convirtió pronto en patrimonio literario de innumerables autores europeos que contaban su historia adaptándola, aumentándola, corrigiéndola o cambiándola, según los casos, a lo largo de lo que quedaba del siglo XVII. Así, habían surgido versiones italianas como las de Cicognini ${ }^{4}$ y Giliberto ${ }^{5}$. De la obra de este último se sirvieron los franceses Dorimon y Villiers para sus creaciones $^{6}$. Cuando Molière decide agregarse al número de autores que habían tratado el tema, la historia poseía ya una cierta solera, pero él parte directamente de las versiones italianas y francesas para crear en 1665 su Dom Juan ou le Festin de Pierre, dotando al protagonista de la facultad de analizar filosóficamente la existencia. El español Alonso de Córdova y Maldonado crea a su vez una versión? a partir del modelo tirsiano pero

\footnotetext{
${ }^{3}$ La primera edición es la de Manuel de Sande, realizada en Sevilla en 1627, que comprendía un conjunto de obras teatrales en un solo volumen. En 1630, Gerónimo Margarit imprime en Barcelona un tomo titulado Doce comedias nuevas de Lope de Vega y otros. Es en esta edición en la que aparece Tirso como autor de El Burlador de Sevilla y combidado de piedra.

${ }^{4}$ A este autor se le atribuye $/ /$ Convitato di pietra, obra fechada hacia 1640. Cicognini, gran admirador del teatro español, habría asistido en 1625 a una representación de la obra española en Nápoles por la compañía de Francisco Hernández Galindo. La creación de Cicognini es una adaptación del sistema teatral español al italiano, fundado sobre la "commedia dell'arte" en la que se acentúa la carga cómica y pintoresca del modelo. ${ }^{5}$ Onofrio Giliberto escribió su obra en 1652 , y aunque perdida es susceptible de ser reconstruida argumentalmente
pues sirvió de modelo a las de Dorimon y de Villiers.

${ }^{6}$ Ambas llevan el mismo título: Le Festin de Pierre ou le Fils criminel, que presenta un contrasentido debido a una mala traducción del término "convitato" por "convito". Fechadas respectivamente en 1658 y 1659 , coinciden no sólo en el título sino en la trama y en la caracterización de un Don Juan libertino y sanguinario.

${ }^{7}$ La Venganza en el sepulcro, de fecha incierta pero presumiblemente dentro de la década de 1660 a 1670 . Es una comedia en tres actos de la que existe únicamente un ejemplar manuscrito ya que nunca fue impresa.
} 
endureciendo sobremanera al personaje al hacer hincapié en la alevosía y premeditación de sus acciones.

El predominio de la razón sobre la pasión para hacer el mal adorna al héroe de Antonio de Zamora en No ay plazo que no se cumpla ni deuda que no se pague y conbidado de piedra, obra presumiblemente representada en 1713 aunque no se publicará hasta $1744^{8}$. En ella sorprende el hecho de que le sea adjudicada una debilidad, la de ser vulnerable, bien a su pesar, ante el amor de una mujer, Ana.

También en el primer cuarto del siglo XVIII, aparecen numerosas versiones flamencas ${ }^{9}$ que enfatizan el castigo del malhechor. En Italia, Goldoni tienta también su suerte ideando un Don Juan no obsesionado por infringir las reglas morales y sociales, y eludiendo el tratamiento del elemento sobrenatural en Don Giovanni Tenorio ossia il dissoluto ${ }^{10}$.

En el terreno musical, en el 1787, Giovanni Bertati escribe el libreto para el Don Giovanni Tenorio ossia Il convitato di pietra de Gazzaniga" ${ }^{11}$, y Da Ponte por su parte, el correspondiente para Don Giovanni de Mozart que se representaría en Viena ocho meses después del estreno de la ópera de Gazzaniga. Cerrando el siglo, Casanova de Seingalt escribe en francés de 1791 a 1798 una Histoire de ma vie también llamada Mémoires en la que a través del relato de sus innumerables aventuras galantes presenta la sociedad de su época. Como ya había ocurrido con Goldoni, la persecución de la felicidad sin atender al placer de la transgresión lo distingue del primitivo Don Juan.

Es curioso señalar que el siglo XVIII no haya producido en Francia ninguna versión relevante sobre el tema de Don Juan. Todo parece indicar que el interés se centra en otras figuras de libertinos como los ideados por Laclos o Crébillon Fils, que lejos del entorno sagrado y sacrílego en el que se mueve el Tenorio, concentran su refinado cinismo en la competencia entre iguales dentro de un microcosmos agnóstico en el que el desafío a Dios no ofrecía ya ningún interés.

No ocurrirá lo mismo con los artistas románticos, que van a encontrar en Don Juan el paradigma del héroe que imaginan. El lado oscuro de un personaje excepcionaimente hermoso y hábil, su faceta más siniestra no podia menos que seducir al autor romántico, que encuentra en el protocolo donjuanesco y sus consecuencias una fuente de muerte, de misterio y de predestinación. El ambiente de la leyenda era el ideal: macabros banquetes nocturnos al que son convidados solemnemente hombres asesinados; dolientes espectros

\footnotetext{
${ }^{8}$ La publicó Joaquin Sánchez en Madrid, en el segundo tomo del recopilatorio: Comedias de Don Antonio Zamora. El éxito del Don Juan de Zamora fue tan grande que desbancó a la obra de Tirso en las representaciones de la obra que se hacian con motivo del día de Todos los Santos y el de los Difuntos, hasta ser desplazada a su vez por el drama de Zorrilla a partir de 1844 .

${ }^{9}$ L. de Fuyter, Don Juan, of de gestrafte ontrouw, 1716; G. van Maater, Don Juan, of de gestrafte vrijgeest, 1719 ; con este mismo título escriben sus obras F. Seegers, y J. van Rijndorp en 1721; F. Rijk, Don Pedroes geest of de gestrafte baldaadigheit, 1721.

${ }^{10}$ Hay constancia de representaciones de esta obra desde 1736, sin embargo no sería editada hasta 1760.

11 Se trata de una representación musical en un solo acto y veinticinco escenas, representada en el carnaval de Venecia de 1787.
} 
que acuden puntualmente a la cita y proponen a su vez nuevos encuentros en siniestras capillas. El tiempo escogido en armonía con esta atmósfera era asimismo muy adecuado: la noche se convertía en coprotagonista de una historia en la que los peligros y el crimen acechaban por doquier.

Pero es que además en Don Juan descubren los románticos la rebeldía por antonomasia, el hombre capaz de enfrentarse a cualquier otro, a la sociedad entera y al Ser supremo. Pasando por encima de la ley humana, de la moral establecida, de la religión en la que ha sido iniciado, llega a medirse con su creador. Si su final habitual había sido hasta entonces el castigo a su desobediencia, el nuevo Don Juan se convierte en dueño de su propio destino al ir al encuentro de su fin sin que nadie lo obligue a ello. Parece así que ni siquiera su aniquilamiento lo convierte en vencido. Esta decisión libre de enfrentarse al poder supremo a sabiendas de que eso le costará la vida le da al personaje dimensiones trágicas.

Así provisto de grandeza heroica, le añaden además a su bagaje los románticos la dificultad de una misión, la búsqueda de la mujer soñada, que resultará infructuosa. La persecución de este ideal justifica la seducción y el abandono de todas aquellas mujeres que nunca resultan ser la perfecta. Esta pasa a ser el pretexto e incluso la causa de la perpetua huida de Don Juan, que se ve impelido a seguir buscándola a través de ciudades y países. Curiosamente, aquel que sustancialmente era el paradigma del engaño pasa a ser alguien que se entrega al cumplimiento ineludible de una empresa: el verdugo se había convertido en víctima de su obsesión.

Dentro de la producción del XIX, desde 1813 -fecha de publicación del Don Juan de Hoffmann- hasta 1839 en que Sand publica la segunda edición corregida de Lélia, algunas versiones del mito aportan cambios trascendentales. E. T. A. Hoffmann, admirador de Mozart hasta la idolatría, escribe un Don Juan ${ }^{12}$ al que se disputan Dios y el Diablo. Decepcionado por la búsqueda estéril de la mujer de sus sueños, decide hacer a todas las representantes del sexo femenino objeto de su venganza. Sin embargo, la mujer a la altura de Don Juan existe para Hoffmann. Esta es Ana, que llega demasiado tarde, cuando Don Juan se ha convertido en un depravado irredimible. Loca de amor por él, al comprender que no podrá conseguirlo, provoca la muerte de su amado al atraer sobre él el castigo del cielo.

A pesar de la mala acogida por parte de la crítica de los dos primeros Cantos del Don Juan de Byron, este poema inacabado (1819-1824) tuvo un gran éxito popular, convirtiéndose en fuente de inspiración para todos aquellos autores que tocaron el tema, Sand incluida. La idea de hacer un anti-Don Juan -ya que su personaje es un eterno adolescente, ingenuo, y seductor a su pesar- la aprovecharían otros autores. Sand por su parte intentará la subversión del mito aunque desde otros parámetros menos favorecedores para el personaje.

El Don Juan Belvidéro que Balzac ideó en L'Elixir de longue vie en 1830 ignora esa vía de justificación iniciada por Hoffmann e incluso se precipita por sí mismo en el infierno al

${ }^{12}$ El título completo es Don Juan. Eine fabelhafte Begebenheit, die sich mit einem reisenden Enthusiasten zugetragen. Este relato forma parte de la obra Phantasiestücke in Callots Manier, publicada en cuatro volúmenes de 1814 a 1815 por el editor Kunz, en Bamberg. 
rechazar la canonización final que pretende procurarle Elvire. Reanimado sólo en parte por el elixir que debía hacer resucitar a su padre y que él le negó guardándolo para él mismo, su cabeza y su brazo se convierten en objeto de veneración de los fieles. Horrorizado ante la idea de convertirse en santo, su cabeza resucitada asesina a dentelladas al abad, a la vez que blasfema y reniega de Dios.

Mucho menos diabólico es el Don Juan que Alfred de Musset idea en dos de sus producciones. La primera de ellas, Namouna, es un largo poema publicado en 1832 dentro del cual se alude al personaje en el Canto II. Musset distingue tres Don Juan, uno vulgar que identifica con el de Molière; uno de más altura que identifica con Valmont, y el que considera auténtico y aún por crear, aquel que se ve obligado a errar en busca de un ideal imposible y muere fulminado, entregándose al destino. Es a este último al que Musset califica muy benévolamente de "candide corrupteur" y de "Prêtre désespéré"13.

En la segunda de sus creaciones Musset parece tentado por mostrar otra faceta del personaje, bastante más frívola y nada espectacular. En $1833^{14}$ aparece en la revista $L a$ France littéraire lo que no llegó a ser más que un fragmento teatral. Bajo la mención "Scène première", este arranque hacía prever la continuación de una obra que llevaba por título Une Matinée de Don Juan y que nunca se completó. En dicho fragmento Don Juan aparece sumido en un hastío del que pretende salir pidiendo a Leporello que le lea la lista de sus conquistas en Francia. Los comentarios sarcásticos del seductor sobre cada mujer rememorada componen una escena humorística que muestra el menosprecio por todas las féminas que constituyen el repertorio de este libertino displicente y cínico.

Otros autores franceses desarrollarán en cambio la idea de la redención del personaje. Lo que la Elvire de Balzac no pudo conseguir, lo provoca en cambio la visión del propio entierro del que en 1834 Prosper Mérimée llama Don Juan de Marana en Les Ames du Purgatoire. Este personaje, híbrido de Don Juan Tenorio y Miguel de Mañara, después de una vida de corrupción y de crímenes muere en olor de santidad, tras haberse arrepentido y haber tenido tiempo de hacer el bien. Independientemente de los guiños de tono irónico que Mérimée hace al lector por medio de su narrador y que hacen pensar en una caricatura del género hagiográfico, el relato culmina con la total rehabilitación del malvado aunque no por medio de la intervención de una mujer sino por la evidencia del poder celestial.

Será Blaze de Bury quien en el drama lírico Le Souper chez le commandeur en el mismo año de 1834 otorgará al sexo femenino el honor de convencer a Don Juan para que renuncie a su vida anterior. Esta orientación imprime un cambio de rumbo fundamental al mito ya que otorga al amor un sentido místico del que carecía hasta entonces. Esta nueva perspectiva será muy bien acogida por muchos continuadores del mito, entre los que se encuentra el español Zorrilla quien, diez años después hará que su Don Juan sea redimido gracias a la intercesión de Doña Inés.

\footnotetext{
${ }^{13}$ A. De Musset, Premières poésies, Paris, Garnier, 1958, pp. 268-269.

${ }^{14}$ Parece conveniente señalar que éste es el año en que después de haber roto con Jules Sandeau, George Sand conoce en casa de Buloz a Musset del que se convierte en amante en el mes de junio. La primera edición de Lélia ve la luz en julio.
} 
En 1837 Alexandre Dumas padre ofrece en Don Juan de Marana ou La Chute d'un ange una solución distinta -que nos parece fundamental para la segunda versión de Lélia-, a caballo entre Mérimée y Blaze de Bury. Dumas recurrirá a la religiosa Marthe, un ángel hecho mujer por la gracia divina, que baja del cielo con la misión de redimir a Don Juan. Al enamorarse el ángel de Don Juan -como era previsible- provoca la condenación de ambos. En una versión posterior sin embargo, Dumas decidiría dar un final feliz a la historia, haciendo que Don Juan se salvara por intercesión del ángel al que corresponde en su amor.

En este entorno interesado por el mito donjuanesco, en el que muchos contemporáneos deciden abordar el tema aparece, como ya se ha adelantado, Lélia ${ }^{15}$. La edición de 31 de julio de 1833 del manuscrito entregado el 1 de junio anterior, representa la primera obra que su autora firma como George Sand ${ }^{16}$, con esta ortografía a la inglesa.

Lélia pertenece al subgénero de la novela mística, por cuanto resalta el tema abstracto del progreso espiritual de la mente humana sobre la simple intriga. En el prefacio de la edición de 1839, Sand la califica de ensayo poético y de novela extraña ${ }^{17}$, "un livre assez obscur pour moi-même" 18 , aunque muy apreciado hasta el punto de considerarlo su mejor obra $^{19}$. El comité de redacción de la La Revue des deux mondes la anunció como la antítesis de distintas categorías novelísticas pertenecientes a una poesía que denominaba "visible" y que se plasmaba en novelas pseudohistóricas, psicológicas o de aventura, basadas fundamentalmente en la emoción y no en la reflexión. En este sentido, dicho comité saludaba la nueva obra como una creación revolucionaria. En efecto, Sand arriesga en ella una nueva concepción de novela que aglutinaba elementos autobiográficos, psicológicos, reflexiones filosóficas, confesiones y pinceladas de novela gótica.

La técnica narrativa era también muy novedosa, ya que no presentaba la clásica voz del narrador de principio a fin, sino que mezclaba la estructura de la novela epistolar con la polifonía narrativa. La intención era la de ofrecer una voz asexuada, por ser masculina y femenina al mismo tiempo, necesariamente andrógina al pretenderse igualitaria en un mundo en que la mujer permanecía relegada a ciertos papeles, dentro de los que no se concebía en ningún caso el de organizadora del mundo, ya fuera éste real o virtual.

\footnotetext{
${ }^{15}$ A lo largo del artículo nos referiremos a la edición de P. Reboul (1986), Paris, Ed. Garnier, Coll. Classiques Garnier, 1960. Dicha edición contiene las dos versiones de Lélia de 1833 y 1839.

${ }^{16}$ En 1831 Rose et Blanche se había publicado como obra de Jules Sand, seudónimo que encubría a dos autores: Jules Sandeau y Aurore Dupin, convertida desde los dieciocho años en Aurore Dudevant por su matrimonio con el barón Dudevant. En 1832, como ya hemos indicado más arriba, ven la luz las novelas Indiana y Valentine y el relato corto Melchior bajo el pseudónimo G. Sand. En diciembre del mismo año otro relato corto, La Marquise, se publica bajo la firma Georges Sand, según la ortografia convencional francesa.

17 "Lélia a été et reste dans ma pensée un essai poétique, un roman fantasque, où les personnages ne sont ni complètement réels, comme l'ont voulu les amateurs exclusifs d'analyse de moeurs, ni complètement allégoriques, comme l'ont jugé quelques esprits synthétiques (...)", G. Sand, Lélia, op. cit., p. 350.

${ }^{18}$ Así califica su obra en una carta al notario N.-H. Cellier-Dufayel, Correspondance, Georges Lubin éd., 25 vols., III, 93, Paris, 1964 - 1991.

${ }^{19}$ Eso afirma en una carta de 14 de mayo de 1836 , Ibíd., III, p. 364.
} 
La obra comienza con el discurso de un sujeto no identificado, discurso que resulta ser el texto de unas cartas cruzadas entre Lélia y Sténio; sigue con dos párrafos narrativos en tercera persona y con un diálogo entre Sténio y Trenmor. A través de las miradas extasiadas de estos personajes masculinos ante la aparición de Lélia en un baile de disfraces, asiste el lector a la descripción de la protagonista. Se vuelve luego a la correspondencia entre Lélia, Sténio y Trenmor, para continuar con la voz de un narrador en tercera persona y diálogos a cinco voces.

Confidencias, profesiones de fe ideológicas, conversaciones de unos personajes con otros hacen de esta obra un precedente de la novela de ideas del XIX que los novelistas rusos llevarían a su punto álgido en la segunda mitad del siglo. Ni contenido ni forma pueden encasillarse en moldes anteriores. Lélia es una "summa" ambiciosa que ignora el propósito de distraer y que, en cambio, persigue traducir en palabras la conciencia del hombre, convirtiéndose en muestra de la nueva literatura que Sand defendió en otros trabajos teóricos ${ }^{20}$.

Sea como fuere, la excentricidad de la obra desató una polémica, muy productiva para la autora, que dividió a los críticos y al público lector en partidarios y denostadores. Entre los primeros, Sainte-Beuve calificó la novela de lírica y filosófica, mezcla de realidad y de imposible ${ }^{21}$. Musset fue aún más allá presentándola como estandarte de la nueva escuela literaria a la que pertenecían Sainte-Beuve, Senancour y él mismo, escuela que se concentraba alrededor de La Revue des deux mondes, practicando la descripción de personajes solitarios, indiferentes a la sociedad, cuestionadores de todo lo espiritual y representantes del mal moral del siglo. Si bien es cierto que Musset limitaba bastante el número de páginas de la obra auténticamente logradas en su opinión, a cambio consideraba que había en Sand un antes y un después de Lélia ${ }^{22}$. Los oponentes, agrupados en torno a L'Europe littéraire y para quienes el paradigma de la perfección eran Balzac y Hugo por su representación de la imagen concreta, veían en la independencia que propugnaba Sand, una falta de responsabilidad y solidaridad social, y en el espiritualismo a ultranza una abstracción exagerada.

\footnotetext{
${ }^{20}$ Concretamente en Questions d'art et de littérature: "Une autre littérature se prépare et s'avance à grands pas, idéale, intérieure, ne relevant que de la conscience humaine, n'empruntant au monde des sens que la forme et le vêtement de ses inspirations, dédaigneuse... de la puérile complication des épisodes, ne se souciant guère de divertir et de distraire les imaginations oisives, parlant peu aux yeux mais à l'âme constamment", Paris, CalmannLévy, 1878, p. 42.

${ }^{21}$ Lo cierto es que Sainte-Beuve se hizo bastante de rogar antes de realizar una reseña de la obra en Le National de 29 de septiembre de 1833, recogida posteriormente en Sainte-Beuve, Portraits contemporains, 5 vol., Paris, Calmann-Lévy, 1881, I. Si bien reconocía en Sand los valores de una escritora combativa, la reseña contenía una crítica sobre ciertos excesos incontrolados en la concepción y el seguimiento de los temas tratados, asi como de algunos defectos de estilo que lo hacían demasiado culto y poco sereno. Terminaba con el consejo a la autora de que volviera a una novela que él calificaba de real y de que abandonara la ironía y la invectiva excesivamente patentes para su gusto en Lélia.

${ }^{22}$ El siguiente comentario aparece en una carta sin fechar dirigida a la escritora en George Sand - Alfred de Musset. Correspondance, éd. Louis Evrard, pp. 26-27: "Il y a dans Lélia, des vingtaines de pages qui vont droit au coeur, franchement, vigoureusement, tout aussi belles que celles de René ou de Lara. Vous voilà George Sand; autrement vous eussiez été madame une telle, faisant des livres".
} 
Dado que no subyace en Lélia una historia de envergadura, son los personajes los que constituyen la intriga al representar las distintas actitudes sobre las que gira la novela: Pulchérie encarna el epicureísmo; Sténio la credulidad, la confianza en el futuro, el amor; Lélia el escepticismo, la decepción y la desconfianza; Trenmor el vicio rehabilitado por el castigo y la resignación; Magnus el fanatismo religioso. Todos son sin embargo presentados como pertenecientes a una novela de aprendizaje ya que van evolucionando al pasar por distintos estados de ánimo: "du désabusement au désespoir, du désespoir au doute, du doute à l'ironie, de l'ironie à la pitié et de la pitié à la résignation sereine et impassible, au dédain religieux et grave de tout ce qui n'est pas Dieu ou la Pensée"23. Sténio deriva de la confianza ciega a la desesperación que le lleva al suicidio, Trenmor de la delincuencia al estoicismo, Magnus del fanatismo al ateismo. En este sentido no debió asombrarle a Sand el proteico Don Juan de Mérimée, que un año depués de Lélia veía la luz para presentar al lector la carrera fulgurante de un criminal corrompido y corruptor que llega a convertirse en un santo entregado a los pobres, enfermos y desheredados de la humanidad.

Los personajes de Lélia son parte de un repertorio de las posturas ideológicas de la época de su credora. Entre ellos, Lélia representa el espiritualismo engendrado por el ya citado mal del siglo, el sufrimiento atroz de quien, en cualquier terreno, desea culminar una pasión y no puede, el enfrentamiento a la impotencia sexual y/o intelectual. Sand analiza a través de ella la maligna apatía que afectaba a la sociedad en que le había tocado vivir, la indiferencia moral, la inercia existencial, marcas de la decrepitud de un mundo en vías de desaparición. Ello desencadenaba una melancolía enfermiza, un "spleen" cuyo único antídoto consistirá para Lélia en la confianza en la poesía. Dentro del cuadro metamórfico, la heroína supera finalmente la apatía para acceder a la salvación por medio de la literatura. La misma solución se adopta posteriormente en Lettres d'un voyageur. Su narrador, aquejado del mal del siglo, emprende un viaje por los Alpes italianos en busca de un remedio para su melancolía, encontrándolo precisamente en la redacción de un diario de viajes.

Sand no vacila en dotar a Lélia de valores que se habían considerado tradicionalmente masculinos, como la racionalidad, el escepticismo, la frialdad o la inteligencia. Esta equiparación se quiere mostrar por medio de los signos externos del atuendo: en el pasaje del baile de disfraces, Lélia aparece vestida de hombre, determinación que la escritora había tomado en su vida personal como es harto sabido, probablemente por los mismos motivos que su personaje. Aunque en Histoire de ma vie explica que había decidido adoptar la vestimenta varonil exclusivamente porque le suponía ahorro -ya que la ropa de mujer resultaba mucho más cara- y comodidad al tener que desplazarse por los barrios bohemios de París, a la par que le permitía el acceso a los círculos intelectuales, y el acudir a los sitios sin compañía masculina, indudablemente debían existir otras razones más fuertes que autorizaran una decisión tan extravagante en aquella época. No es aventurado interpretar su opción indumentaria como un paso hacia la igualdad con el hombre, incluso hacia la superación de éste, ya que la ropa masculina le permitía integrar los dos sexos, su condición femenina natural y la masculina adquirida por el travestismo. Si bien es cierto que la

\footnotetext{
${ }^{23}$ George Sand, "Romans et nouvelles", en Questions d'art et de littérature, op. cit., p. 48.
} 
androginia era un tema tratado por algunos románticos franceses en sus obras ${ }^{24}$, el hecho de adoptar normalmente en la vida real una apariencia hermafrodita era inusual. Resultaba de esta decisión la apariencia de un ser fuerte y autosuficiente que tendía al conocimiento absoluto.

En este sentido, Isabelle $\operatorname{Hoog}^{25}$ afirma que Lélia representa el modelo perfecto de la mujer solitaria al confesar abiertamente su frigidez y considerar el matrimonio como una esclavitud para la mujer. Sin protección ni vigilancia de padre o marido, encarna el deseo romántico de soledad femenina que ya había expresado su creadora en Indiana y en Valentine. Esta soledad le acarreará a la heroína efectos desastrosos, como la caída en un infierno psicológico y en la sinrazón pero a cambio, le otorga un rango de personaje filósofo equiparable al René de Chateaubriand, al Obermann de Senancour o al Raphaël de Valentin de Balzac, por plantear el dramático desfase entre idealismo y realidad. Todos ellos en suma, víctimas de la posterioridad de la época gloriosa de Napoleón, la Restauración ${ }^{26}$, periodo durante el que una vida intelectual demasiado intensa conduce a la constatación de las ilusiones perdidas.

Dentro de la Lélia de 1833 se encaja de forma vistosa un monólogo pronunciado por Sténio dedicado a Don Juan. Ubicado en la quinta y última parte, ocupa una extensión considerable del capítulo XI, penúltimo de la obra. Éste es fundamental pues contiene la muerte violenta de Sténio, su suicidio arrojándose al lago. No resulta sorprendente la inclusión en la obra de una interpelación al personaje mítico que desafía y ultraja a Dios con el deseo de recibir una respuesta que resuelva la duda sobre la existencia de éste, planteada por el silencio del Ser superior. De forma paralela a Sténio, la autora parece plantear su incredulidad en Dios con la intención de negar su existencia, no sin dirigirse a él como interlocutor reprochándole su creación. En este sentido hay una disposición especular dentro de la que Don Juan, Sténio y la propia George Sand se enfrentan con idéntica arrogancia a lo intangible.

La escena tiene lugar en un espacio inequívocamente romántico, un cementerio situado sobre un precipicio desde el que se puede contemplar un lago. En la noche se pueden escuchar los silbidos de las culebras y observar el vuelo de los murciélagos entre los

\footnotetext{
${ }^{24}$ Baste citar a Latouche con Fragoletta, a Balzac con Seraphita, a Stendhal con Lamiel, o a Gautier con Mademoiselle de Maupin.

${ }^{25}$ George Sand L'écriture ou la vie, Paris, Champion, 1999. Esa soledad proviene según Hoog de un aislamiento voluntario que le permite reflexionar a placer y concuerda perfectamente con el topos del desierto, lugar elegido por Lélia para la meditación: "La nature sauvage esı le paysage romantique par excellence. II représente la prédilection des romantiques pour une tierre vierge à l'état brut, lieu qui est riche de multiples connotations. En fin de compte, "le désert" exprime par métonymie l'isolement de Lélia par rapport au monde. Dans le chapitre intitulé "Solitude", Lélia reste seule pour réfléchir et pour rêver. Elle envisage la solitude comme un allègrement de l'être", p. 155.

${ }^{26}$ Según P. Reboul es este planteamiento el que salvaguarda la obra al hacer que, a pesar del arcaísmo de ciertos pasajes, no haya perdido actualidad. Reboul equipara este desgarro al de la posguerra del segundo confrontamiento mundial: "ce désespoir lucide qui l'apparente à quelques oeuvres majeures de notre après-guerre. L'époque où Lélia fut écrite était, comme la nôtre, une époque de rupture. Sand ici, participe à la fois du positivisme (au sens le plus vague du terme) et du spiritualisme le plus mystique. Ce besoin de l'Esprit (survivance et prévision) ruine une Science qui n'apporte que des vérités vaines", Lélia, op. cit., LXVI.
} 
sepulcros. Sténio llega allí acompañado del monje Magnus a quien interroga para conocer el desarrollo de su pasión por Lélia, que le ha llevado a renegar de Dios y a la locura. Sténio quiere saber si Magnus ha renunciado sinceramente a la mujer y se ha liberado definitivamente de su hechizo demoníaco. Para ello, en un pasaje que puede recordar al del pobre de Molière, obliga al monje a jurar por Cristo que sus respuestas van a ser sinceras ${ }^{27}$.

Detectando por las contestaciones de Magnus la poca solidez de su fe, Sténio toma partido por la incredulidad y comienza a hacer balance de su vida preparando su muerte. Todo parte de su primera juventud durante la cual perseguía la quimera de hacer realidad el fantasma del amor. Para ello sintió la obligación de entregarse a gran número de mujeres que identifica metafóricamente con un "troupeau", término que reaparecerá curiosamente en el poema Don Juan aux enfers de Baudelaire ${ }^{28}$ (1964: 47), y que enumera por medio del clásico procedimiento del catálogo ${ }^{29}$.

Partiendo de que la mujer representa esencialmente la mentira y el hombre la vanidad, Sténio culpa a Don Juan de su perdición ya que ha tomado al seductor como modelo. Al recordar cómo hizo de él un objeto de veneración, esperando así estar por encima de las leyes humanas: "Sois mon étoile et mon Dieu" 30 , demuestra mucha menos fuerza que uno de sus antecesores franceses, el Don Juan de Dorimon, que no admitía a nadie por encima de sí mismo: "Je suis mon Roy, mon Maistre, et mon sort, et mes Dieux"31.

Más presente parece estar en el discurso de Sténio, el correspondiente que dirige Musset a Don Juan en Namouna y no precisamente porque lo apruebe sino por las respuestas que Sand opone a sus interrogantes. Como ya señalamos más arriba, Musset presentaba a Don

\footnotetext{
27 ". (...) ce froc vous donne à tous le même langage, comme il vous donne la même démarche; voulez-vous réellement m'être utile? Jurez!

-Je jure de vous répondre, reprit le moine tremblant.

-Par le Christ? dit Sténio.

-Par le Christ, puisqu'il s’agit de votre salut.", op. cit., pp. 285-286.

${ }^{28}$ En el texto de Sand se puede leer: "à mesure que mon âme s'est lassée de chercher dans les bras d'un troupeau de femmes le baiser extatique que Lélia seule pouvait donner", op. cit., p. 288. En el poema de Baudelaire, publicado en L'Artiste en 1846 e incluido en Les Fleurs du Mal, encontramos:
}

"Montrant leurs seins pendants et leurs robes ouvertes,

Des femmes se tordaient dans le noir firmament,

Et, comme un grand troupeau de victimes offertes,

Derrière lui trainaient un long mugissement."

\footnotetext{
${ }^{29}$ Este repertorio, nada ajeno al imaginado por Da Ponte en el Don Giovanni de Mozart: "Nella bionda egli ha l'usanza /Di lodar la gentilezza; / Nella bruna, la constanza; / Nella bianca, la docezza. / Vuol d'inverno la grassotta, / Vuol d'estate la magrotta; / Ė la grande maestosa, / La piccina è ognor vezzosa,/ (...) Ma passion predomiannte / È la giovin principiante", Madrid, Cátedra, 1992, p. 76, comienza con una variante del colectivo troupeau: "Essaim de femmes aux blonds cheveux, aux tresses d'ébène, aux pieds d'ivoire, aux brunes épaules, filles pudiques, rieuses débauchées, vierges aux timides soupirs, Messalines au front d'airain, vous toutes, que j'ai possédées ou rêvées", p. 289. El grupo que estas mujeres constituyen le da aún más relieve a la individualidad incomparable de Lélia.

${ }^{30}$ Ibid., p. 290.

${ }^{31}$ Villiers, Le Festin de pierre ou le Fils criminel, 1659, en Le Festin de pierre avant Molière, ed. de G. Gendarme de Bévotte, La légende de Don Juan, Corrély, 1907, reed. Slatkine, 1978, p. 178.
} 
Juan como un hombre en busca de la mujer soñada y jamás encontrada, fracaso que justifica todas las seducciones de las demás mujeres, encarnaciones insuficientes del ideal que le impulsa a huir y a errar despreciando la realidad. Este delirio amoroso no es para él sino el aglutinante de los deseos de eternidad, de poder y de realización, atractivos en tanto en cuanto no se han colmado aún, y presumiblemente no se han de colmar jamás. Don Juan es para Musset un héroe con más virtudes que sus antecesores. Todo se le puede disculpar en aras de esa búsqueda infructuosa pero enardecida del ideal. Es contra esta redención contra la que reacciona contundentemente Sand por boca de Sténio, juzgándolo y condenándolo. Lo maldice al darse cuenta de que ha estado poseído por él cuando la frivolidad de la pasión ya no le tienta. Le echa en cara el mancillar a las familias, el desprecio de la autoridad, la transgresión de la norma monogámica, el asesinato de padres, maridos y prometidos.

Lo que sigue después es realmente nuevo. Por medio de Sténio, Sand se aleja de los tópicos de interpretación del mito donjuanesco para arriesgar una interpretación del comportamiento delictivo, un análisis psicológico del personaje en el que intuye un cierto sadismo. Don Juan disfruta al oir los suspiros y los gemidos, al percibir el tormento y la angustia que sabe procurar a sus presas. A ellas las convierte en esclavas temerosas de perder los favores del amado e incluso en disimuladoras de la tristeza que les procura el desdén de éste, para no perturbar en modo alguno su momento de placer. Pero sobre todo no imagina siquiera la posibilidad de que ellas también pueden estar a la altura de la inconstancia masculina. Sténio pasa del ataque directo de Don Juan a la defensa de la mujer moderna, liberada de la condición de objeto, rebelde ante el inmovilismo intelectual, alzada contra el masoquismo que supone encontrar la razón del placer amoroso en la presunción del abandono por parte del amante; una mujer capaz de ofrecer belleza, amor y confianza pero en modo alguno sumisión.

Por medio de una serie de antítesis, Sand plasma en este capítulo uno de los mejores fragmentos de la obra:

“Croyais-tu qu'un jour le délire arracherait aux lèvres de ta victime une promesse impie, et qu'elle s'écrierait: "Je t'aime, parce que je souffre; je t'aime, parce que je sens à tes baisers qui se ralentissent, à tes bras qui s'ouvrent et m'abandonnent, que tu seras bientôt las de moi et que tu m'oublieras. Je me dévoue, parce que tu me méprises; je me souviendrai, parce que tu m'effaceras de ta mémoire. Je t'élèverai dans mon coeur un sanctuaire inviolable, parce que tu vas inscrire mon nom sur ton livre dédaigneux et insultant"?"32.

Don Juan es tratado de loco, de fatuo, de absurdo; desprovisto del lustre de héroe y reducido a un "libertin sans coeur, une âme de courtisan effronté dans le corps d'un valet de charrue ${ }^{\prime 33}$. Incluso admitiendo que siga siendo esa gran idea personificada, en la que Nodier aconsejaba que consistiera todo personaje literario y que Sand incluyó en su estética, Don Juan ha dejado de ser un guía. Sin embargo, en el colmo de la desesperación, Sténio actuará de forma comparable a otros Don Juanes del mito que al verse acosados por la muerte cercana se vuelven hacia Dios, blasfemando a la espera de una última reacción.

\footnotetext{
${ }^{32}$ Op. cit., p. 293.

${ }^{33}$ Ibidem.
} 
Aunque es Sténio el que tiene presente a Don Juan como modelo diabólico, es Lélia la auténtica seductora que lleva a los hombres a la perdición, y quien se perderá también con ellos. Es ella quien es capaz de seducir hasta la locura a un joven inocente y a un miembro de la iglesia, un monje casuista, equivalente de la figura de la monja, presente en versiones anteriores del mito. Esta presencia sacrílega en el repertorio de conquistas de una persona consagrada a Dios será utilizada por muchos de los autores románticos posteriores como Mérimée, Alexandre Dumas padre o Zorrilla. El propio Musset, en Une matinée de Don Juan, incluye en la lista de seducciones que Leporello va desgranando para deleite de su señor a una hermana de la Caridad ${ }^{34}$. Entre otras razones, por esa capacidad de desafiar incluso a Dios seduciendo a uno de sus monjes, Lélia, auténtica Don Juan, puede haber desplazado en la edición de 1839 a Sténio, arrebatándole su discurso.

La primera versión de Lélia representó un éxito al que no fueron ajenas las críticas despiadadas que no hicieron sino aumentar las ventas. El editor Dupuy declaró haber hecho una tirada de 1.500 ejemplares en la primera edición, lo cual representaba un récord para la época. Sin embargo, Sand no pasó por alto las críticas y modificó la obra sobremanera seis años después, renunciando a las innovaciones narrativas que habían chocado excesivamente tanto al público común como al especialista, para volver a la forma tradicional del relato en tercera persona, fórmula que utilizaría no sólo en esta nueva Lélia sino en sus novelas posteriores.

Pero podrían señalarse otras causas, menos profesionales, de la profunda remodelación. El acuerdo firmado con Buloz a finales de 1834 para la publicación de sus Obras Completas la obligaba a la revisión de todas sus creaciones hasta la fecha ${ }^{35}$, compromiso que no cumplió por lo que suponía de gravoso. No obstante, en el caso de Lélia, decidió alterar su mensaje por medio de correcciones e incluso añadirle un tercer volumen. Las razones para la adulteración de una obra que muchos habían calificado de escandalosa ${ }^{36}$, obedecían al proceso de su separación matrimonial que estaba entonces en marcha y durante el cual convenía a la escritora observar una actitud pudorosa y contenida, inconciliable con el cuestionamiento contundente de costumbres y creencias. En concreto, se imponía la supresión de los pasajes sobre la impotencia de Lélia para dejar de herir sensibilidades.

\footnotetext{
34 "Trois figurantes; Emma, modiste; une soeur de la Charité, inconnue." El esbozo de la obra habia aparecido en La France littéraire el mismo año de la publicación de la primera versión de Lélia.

${ }^{35}$ El conjunto estaba compuesto por Indiana, Valentine, Lélia, Le Secrétaire intime et nouvelles, Jacques, André, y Leone Leoni. Sand renunciaba a la propiedad de estas obras e incluso a la de unas memorias que estaban aún por escribir y que estaba previsto fueran publicadas únicamente de forma póstuma. En el artículo II del acuerdo se decia: "Mme Dudevant reverra chaque ouvrage qui fait l'objet du présent traité avant de le mettre sous presse, afin que l'édition nouvelle puisse porter le titre: édition nouvelle, corrigée et revue par l'auteur", Correspondance, éd. de G. Lubin, 19 vols., t. II, n 860, Paris, Garnier, a partir de 1964.

${ }^{36}$ Así, en 1833, Alfred Désessarts afirmaba en La France littéraire: "ce livre me semble dangereux, non parce qu'il ruine quelques idées modernes existantes et gouvernantes (...), mais parce qu'il ne prépare rien”. Por su parte, Capo de Feuillide prevenía en L Europe littéraire de 9 y 22 de agosto del mismo año de forma dramática a sus lectores sobre el poder corruptor de la obra: "Le jour où vous ouvrirez Lélia, renfermez-vous dans votre cabinet pour ne contaminer personne. Si vous avez une fille dont vous voulez que l'âme reste vierge et naïve, envoyez-la jouer aux champs." Por su parte Le Petit Poucet de 1 de septiembre del mismo año era aún mas explícito al calificar Lélia de "oeuvre de dévergondage et de cynisme".
} 
También había motivos de índole filosófica, política y personal. Su militancia en las filas progresistas, la amistad entablada con el socialista Pierre Leroux que le infundió su doctrina antimaterialista y su romanticismo místico, la admiración confesada de Sand por Jean Raynaud y su relación amorosa con Michel de Bourges no concordaban ya con un libro sobre la desesperación, el nihilismo y el autismo de ciertas clases sociales de élite. Las modificaciones debían ir encaminadas a hablar de esperanza, de progreso y de compromiso socialista sobre una base totalmente antagónica. Con este giro, Sand pretendía aplicar a la vida real la teoría de la verosimilitud de la metamorfosis ideológica del personaje.

Se trataba realmente de hacer una obra nueva aprovechando una antigua, ardua labor que Sand no pudo llevar a cabo, acuciada como estaba siempre por simultanear múltiples trabajos. Finalmente, redujo las correcciones y las innovaciones al mínimo aunque el cambio de timón ideológico se imponía de todas maneras: Lélia se retira a un convento y se convierte en abadesa; Trenmor sufre un nuevo deslizamiento en su comportamiento: si en la Lélia I había pasado de malhechor a filántropo, en la II pasa de hombre de reflexión a hombre de acción. Las consecuencias son significativas: la primitiva Lélia se convierte en el modelo que no hay que seguir, la nueva en cambio es realmente otra persona que expresa su fe en Dios, en el progreso y en el ser humano. En este sentido afirma P. Reboul que "Celle qui était athée en amour trouvait l'amour et le bonheur dans la charité universelle"37. El optimismo sustituía así a la duda y el futuro se acometía con vitalidad y esperanza.

En un pasaje del capítulo LXII, Lélia se dirige a un público femenino de novicias y seglares para llamarlas al rechazo de las vanidades y al amor infinito. Sténio asiste a la conferencia teológica disfrazado de mujer y le propone un dilema a la oradora: la mejor manera que tiene una mujer de convertir a un pecador es amarlo tal como cuenta la versión de la leyenda de Don Juan en la que un ángel hecho mujer enviado por Dios para salvarlo se enamora del transgresor, es decir según la idea de Dumas en Don Juan de Marana ou La Chute d'un ange, que se había publicado tres años antes de la segunda versión de Lélia. La abadesa reacciona pronta e inteligentemente dando una continuación a la historia y haciendo hincapié en que el desenlace es la condena de los dos. A partir de aquí enlaza con el discurso de Sténio de menoscabo de Don Juan, ya presente en Lélia I y que se transcribe en Lélia II íntegramente.

Añade luego para ilustrar su idea de que hay que someter a Don Juan, el cuadro de la perdición de toda mujer que se deja enamorar por ese hombre diabólicamente encantador. De forma inevitable y rápida, no más allá del tercer día de reñación, a Don Juan le llega el tedio y el suplicio de la enamorada comienza. La abadesa convierte entonces a Don Juan en prototipo, porque según ella hay muchos hombres como él: "Un autre Don Juan se présentera, car il y en a beaucoup dans le temps où nous vivons" ${ }^{\text {"38. }}$. Contra esta legión masculina incapaz de ternura, no cabe por parte de la mujer sino una actitud de desprecio y una opción: la sublimación del deseo sensual mediante inquietudes inmateriales.

\footnotetext{
${ }^{37}$ Op. cit., p. 332.

${ }^{38}$ Op. cit., p. 516.
} 
El efecto perseguido de agradar a un público nuevo se volvió contra su autora. La edulcoración de la primitiva obra no favoreció las ventas. El revolucionario discurso primitivo mudado en sermón panfletario de las nuevas doctrinas sociopolíticas dejó amontonados en el almacén del editor Buloz 1080 de los 1500 ejemplares de la primera tirada. Todo un fracaso. Sand no redimía a Don Juan pero redimía a su heroína, desproveyéndola de su talante demoníaco, reinsertándola en la sociedad mediante su ingreso en el convento y su predicación. Hasta su muerte se desdramatizaba, ya que si en la primera versión era asesinada por el monje, en esta segunda Lélia muere de muerte natural después de haber hecho un discurso que justificaba su vida. En él se mezclan arrepentimiento y reproches al mundo y al Ser superior que lo ha creado por no haberle concedido a ella la ocasión de descubrir dónde está la verdad que buscó afanosamente toda su vida.

Años más tarde Sand vuelve a tratar el tema de Don Juan. 1851 es el año de la publicación gradual de Le Château des Désertes en la La Revue des Deux Mondes de febrero a abril, e integral en la editorial de Michel Lévy en noviembre. Esta novela, que desarrolla y amplía un relato corto anterior de Sand, Célio Floriani, traslada a la literatura la actividad de improvisación teatral alentada por Sand para amenizar las largas veladas invernales de Nohant, con la colaboración entre otros de Frédéric Chopin que proporcionaba el fondo musical, igualmente improvisado. Quizás el hecho de que Chopin fuera autor de variaciones sobre el aria de Don Giovanni denominada por la frase de su incípit, "Là ci darem la mano", no fuera ajeno a la elección del tema que sirve de trama a Le Château des Désertes.

En efecto, en ella unos actores se reúnen en un castillo de Francia en búsqueda de perfeccionamiento interior y profesional, después de haber viajado por Austria e Italia. El proyecto que los ocupa es servirse de distintas versiones del tema de Don Juan, enriqueciendo esta amalgama con aportaciones personales para llegar a crear la obra maestra literaria completa que no había sido todavía lograda - en eso Sand coincide con Musset-, opinión esta de la que son meros portavoces de su autora.

El problema se presenta desde el principio ya que esa compañía asume el compromiso de que el teatro consiste en ser imagen de la vida y ésta a su vez en dar cada cual lo más puro de sí mismo. Si el actor es bello, bueno y verdadero en la vida real, será ineludiblemente bueno y honrado en el escenario. No cabe duda de que este axioma constreñiría mucho la versatilidad de estos actores que no podrían interpretar sinceramente el papel de un desalmado como Don Juan. Por eso Sand prefiere prescindir de lo que Jean Rousset llamará las constantes del mito ${ }^{39}$, y adoptar el modelo del ángel caído de Hoffmann que marca el paso del clasicismo al romanticismo del personaje en cuestión. En la historia de Sand la ética prevalece sobre la estética primitiva. El personaje es demasiado bueno para mantenerse fiel a la condición de Don Juan y se opera en él una metamorfosis. Resulta así que la personalidad ancestral de Don Juan se desmorona al irse escindiendo entre personajes secundarios que aparecen para diluirse inmediatamente como ejemplo de lo que no se debe ser. Es curioso que estos personajes son en su mayor parte femeninos (una

\footnotetext{
${ }^{39}$ Cf. Le Mythe de Don Juan, Paris, A. Colin, 1978.
} 
madre libidinosa, una duquesa cuyo amor propio la impulsa a seducir a los hombres $\sin$ cesar) y se mueven en círculos sociales hipócritas y egoístas. Todos ellos se muestran primero en su apogeo y luego en su decadencia, abandonados por aquellos a quienes tentaron alguna vez.

Lo que podría verse en principio como una exploración del mito resulta ser una novela de aprendizaje en la que Célio, el supuesto Don Juan, no lo es en absoluto. Hay mucho de las ideas de Rousseau en esta novela hasta el punto de que puede afirmarse que Sand propugna aquí la bondad del hombre natural y la solidaridad como germen de la comunidad ideal.

Don Juan es sólo para Sand el punto de referencia, un papel teatral que su personaje Célio Floriani debe interpretar. La conclusión a la que llega es que es incapaz de ello, hasta tal punto de que opera en Don Juan una transformación aniquiladora. Sand quiere demostrar que su concepción del nuevo drama -a saber, la trasposición de una naturaleza buena, justa y apacible, en la que cada uno corresponde al amor del otro y en la que se sabe que la libertad de uno mismo termina en donde empieza la de los demás no deja sitio para Don Juan, personificación de la falsedad y del atropello. No se trata pues de renovar el mito sino, como en Lélia, de acabar con él. Despojado de toda dimensión trágica, Don Juan se convierte en un fantoche que ha perdido contacto con el elemento sobrenatural. En consonancia con esta desmitificación, la estatua resulta también irrisoria y carece de la condición de ejecutor de la justicia divina.

Así, Don Juan se convierte en un pretexto para que Célio comprenda su propio carácter, después de unos primeros momentos en que, al habérsele encargado el papel de Don Juan, llegue a creerse un seductor cruel para con las mujeres coquetas con las que se cruza. A esto se añade un complejo adquirido por culpa de la relación de su madre con un amante mujeriego y vil, del que Célio supuestamente se habría contagiado.

Para él el ideal femenino tiene como modelo la figura materna. Por eso su desasosiego no se calmará hasta casarse con Cécilia -la paronimia de sus nombres presagiaba su compenetración- en quien ve a una digna sucesora de su progenitora. Al sentirse celoso de ella, comprende que está enamorado. Eso lo tranquiliza al pensar que ni en el teatro ni en la vida podrá ya representar el papel de Don Juan. Realmente, su falsa apariencia es una reacción contra los que no respetan las reglas de esa sociedad ideal a la que tiende el grupo.

El texto de Sand sacrifica la leyenda del seductor para ensalzar la figura de la mujer. Don Juan se convierte en un artificio cultural inspirado por una sociedad corrompida. Sand es con esta criatura mucho más implacable que su creador, el cual lo condenaba al fuego eterno sin remisión. La escritora desestima la salida airosa imaginada por otros románticos de convertir al maléfico seductor en un rebelde, en un igual a la mujer en el terreno del deseo. Lo condena al menosprecio y a la inverosimilitud. Aunque lo que pone en su lugar, una sociedad naturalmente perfecta pueda resultar aún menos creíble.

En conclusión, tanto en las dos versiones de Lélia como en Le Château des Désertes Sand acomete la empresa de destronar al personaje y al hombre que habían afirmado su superioridad mediante la sumisión de la mujer. La postura de George Sand en su vida 
personal impregna su interpretación del mito donjuanesco ${ }^{40}$. Se derroca a un ídolo para sustituirlo por otro, el de la mujer autosuficiente que necesita dar pruebas de su independencia igualándose al sexo masculino por medio de variadas artes.

Sand nunca renunció a ser mujer, pero su voz es mezcla de tonos masculinos y femeninos: "Je n'ambitionne pas la dignité de l'homme... Mais je prétends posséder aujourd'hui et à jamais la superbe et entière indépendance dont vous seuls croyez avoir le droit de jouir... Prenez-moi donc pour un homme ou pour une femme, comme vous voudrez" ${ }^{, 4}$. Por medio de la androginia Sand mantenía su femineidad sin perder credibilidad literaria. Seducción, delicadeza e inteligencia al servicio de la consecución de metas profesionales y personales son el aporte de una mujer en un siglo eminentemente masculino.

\section{REFERENCIAS BIBLIOGRÁFICAS.}

BALZAC, H. de L'elixir de longue vie, en La comedie humaine, vol. XI, Bibliothèque de la Paris, Pléiade, 1990.

BAUDELAIRE, Ch., Les fleurs du mal et autres poèmes, Paris, Garnier-Flammarion, 1964.

CASANOVA DE SEINGALT, Histoire de ma vie, Paris, Robert Laffont, 1993.

CORDOVA Y MALDONADO, A. de, La venganza en el sepulcro, incluida en A. Baquero, Don Juan y su evolución dramática. el personaje teatral en seis comedias españolas, Madrid, Editora Nacional, 1966.

PONTE, L. da, Don Giovanni, Madrid, Cátedra, 1992.

BEVOTTE, G. Gendarme de, Le festin de pierre avant molière. dorimon, de villiers, scénario des italiens, cicognini, Paris, Hachette, 1907.

BEVOTTE, G. Gendarme de, La légende de don juan, son évolution dans la littérature des origines au romantisme, Paris, Hachette, 1906-11, Slatkine Reprints, 1978.

HOFFMANN, E.T.A., Contes fantastiques, t. II, n 358, Paris, Garnier-Flammarion, 1980.

HOOG, I., George Sand, l'écriture ou la vie, Paris, Champion, 1999.

BYRON, Lord, Don Juan (trad. B. Laroche), Paris, Massot, 1994.

MARCOU, L. (ed.), Trois don juan (Dumas, Tolstö̈, Espronceda), Paris, Florent-Massot, 1995.

MERIMEE, P., Les âmes du purgatoire /Carmen, Paris, Garnier-Flammarion, 1973.

MUSSET, A. de, Premières poésies, Paris, Garnier, 1958.

ROUSSET, J., Le mythe de don Juan, Paris, A. Colin, 1978.

\footnotetext{
${ }^{40}$ No en vano André Maurois titula su estudio sobre Lélia, Lélia ou La Vie de Georges Sand, Paris, Hachette. 1952.

${ }^{41}$ Correspondance, II, Lettre à Géroult, 6-5-1835, pp. 879-880.
} 
SAND, G., André, Meylan, L'aurore, 1987.

SAND, G., Consuelo et la comtesse de rudoldstadt, 3 vols., Meylan, L'aurore, 1983.

SAND, G., Correspondance, 25 vols., Paris, Garnier, 1964-91.

SAND, G., Histoire de ma vie, oeuvres autobiographiques, 2 vols., Paris, Pléiade, 1970-71.

SAND, G., Jacques, Paris, Michel lévy, 1869.

SAND, G., Indiana, Meylan, L'aurore, 1996.

SAND, G., Le château des désertes, Meylan, L'aurore, 1985.

SAND, G., Le secretaire intime, Meylan, L'aurore, 1991.

SAND, G., Lélia, Paris, Garnier, 1986.

SAND, G., Lettres d'un voyageur, Paris, Garnier-Flammarion, 1971.

SAND, G., Oeuvres complètes, 35 vols., Genève, Slatkine reprints, 1979-80.

SAND, G., Questions d'art et de littérature, Paris, Calmann-Lévy, 1878; Paris, des Femmes, 1991.

SAND, G., Valentine, Meylan, L'aurore, 1988.

MOLINA, Tirso de (atr.), El burlador de Sevilla, Espasa Calpe, 1993.

ZORRILla, J., Don Juan Tenorio, Madrid, Cátedra, 1992.

ZAMORA, A. de, No hay plazo que no se cumpla ni deuda que no se pague y convidado de piedra, Barcelona, Bruguera, 1972. 